\title{
HISTÓRIA E FORMAS JURÍDICAS DE DISTRIBUIÇÃO DE TERRAS NO BRASIL
}

\section{HISTORY AND LEGAL FORMS OF LAND DISTRIBUTION IN BRAZIL}

\author{
${ }^{1}$ Hertha Urquiza Baracho \\ ${ }^{2}$ Iranice Gonçalves Muniz
}

\section{RESUMO}

Costuma-se dividir a história da propriedade rural no Brasil em quatro fases: Sesmarias, Posses, Lei de Terras e República. Neste artigo, analisa-se cada um desses períodos com o intuito de investigar se existe uma relação entre a concentração fundiária no Brasil atual e o regime das sesmarias adotado por Portugal no Brasil-colônia. A Constituição Federal de 1988 proclama como objetivos da República Federativa do Brasil a erradicação da pobreza e da marginalização e a redução das desigualdades regionais no título dos princípios fundamentais. Ademais, o art.170 dispõe que a ordem econômica tem como finalidade a justiça social e a dignidade da pessoa humana e busca a redução das desigualdades regionais e sociais. Seria o latifúndio uma das causas das desigualdades sociais? Como reduzir as desigualdades e concretizar a Constituição? Quanto maior a desigualdade social maior a necessidade de Reforma Agrária?

Palavras-chave: Palavras-chave: distribuição de terras, Constituições, Lei de terras, Código civil, Estatuto da terra

\begin{abstract}
It is often divide the history of land ownership in Brazil in four phases: Sesmarias, Posses, the Land Law and Republic. In this article, we analyze each of these periods in order to investigate whether there is a relationship between land concentration in Brazil today and the system of land grants adopted by Portugal in Brazil colony. The Federal Constitution of 1988 declares the objectives of the Federative Republic of Brazil to eradicate poverty and marginalization and to reduce regional inequalities in the title of the fundamental principles. Furthermore, article 170 provides that the economic order is intended to social justice and the dignity of the human person and its principle the reduction of regional and social inequalities. It would be the large estates of the causes of social inequalities? How to reduce inequalities and achieve the Constitution? The higher the social inequality the need for land reform?
\end{abstract}

Keywords: Keywords: land distribution, Constitutions, Land law, Civil code, Land statute

\footnotetext{
${ }^{1}$ Doutora em Direito pela Pontifícia Universidade Católica de São Paulo - PUC/SP, São Paulo - SP (Brasil). Professor da Universidade Federal da Paraíba - UFPB, João Pessoa - PB (Brasil)

E-mail: herthaurquiza@gmail.com

${ }^{2}$ Doutora em Direito Público pela Universitat Pompeu Fabra - UPF, Barcelona, Espanha. Professora do Centro Universitário de João Pessoa - UNIPÊ, João Pessoa - PB (Brasil)

E-mail: iranicemuniz@yahoo.com.br
} 


\section{INTRODUÇÃO}

O presente artigo tem como objeto a história da distribuição de terras no Brasil, e o objetivo principal é analisar as raízes históricas da distribuição de terras pertencentes à Coroa de Portugal aos habitantes do Brasil-Colônia. Faz-se necessário para este estudo revisitar a aplicação do sistema de sesmarias no território brasileiro, verificar os pontos positivos e negativos da legislação em vigor até 1822, quando o regime das sesmarias foi abolido e passando a vigorar o período das Posses, piorando ainda mais a situação, pois o país ficou sem legislação até a Lei de Terras de 1850; refletir sobre a influência desta desordenada distribuição de terras que contribuiu para a formação dos latifúndios no território brasileiro; e entender em que medida o latifúndio e a má distribuição de rendas contribuem para aumentar as desigualdades regionais e sociais.

O tema é de salutar importância para compreensão da relação entre a concentração fundiária no Brasil atual e o regime das sesmarias adotado por Portugal no Brasil-colônia.

A Constituição Federal de 1988 proclama como princípios da República Federativa do Brasil a erradicação da pobreza e da marginalização e a redução das desigualdades regionais e sociais no título I, dos princípios fundamentais. Ademais, o art.170 dispõe que a ordem econômica tem como finalidade a justiça social e a dignidade da pessoa humana e a redução das desigualdades regionais. Seria o latifúndio uma das causas das desigualdades regionais? Como reduzir as desigualdades regionais e sociais e concretizar a Constituição? Quanto maior a desigualdade social maior a necessidade de Reforma Agrária?

Salienta-se que foi escolhido o método dedutivo para a abordagem desta pesquisa, iniciando-se pelo estudo das sesmarias, passando pela reflexão acerca da distribuição de terras, até a investigação do que dispõe a Constituição Federal de 1988. Quanto à técnica de pesquisa para a coleta de dados, utilizou-se basicamente a pesquisa bibliográfica.

Dividiu-se o trabalho em dois grandes tópicos como: o período imperial para tratar da posse da terra e da lei de terras e o período republicano para tratar da propriedade no século XX, mais precisamente, a constitucionalização da reforma agrária na Constituição Federal de 1988, e o II plano de reforma agrária que possibilita os assentamentos rurais na atualidade. 


\title{
2 PERÍODO IMPERIAL
}

\subsection{Das sesmarias}

A frase de Lima (1954, p.11) é conhecida pela doutrina: “A história territorial do Brasil começa em Portugal” e sintetiza a história de uma época em que prevalecia o poder absoluto dos soberanos e os bens incorporados ao patrimônio da coroa.

Hely Lopes Meirelles analisa a mesma realidade da seguinte maneira:

\begin{abstract}
No Brasil todas as terras foram, originariamente, públicas, por serem pertencentes à Nação portuguesa, por direito de conquista. Depois, passaram ao Império e à República, sempre como domínio do Estado. A transferência das terras públicas para os particulares deu-se paulatinamente por meio de concessões de sesmarias e de data, compra e venda, doação, permuta e legitimação de posses. Daí a regra de que toda terra sem título de propriedade particular é de domínio público. (MEIRELES, 1995, p.455)
\end{abstract}

De modo que é possível visualizar através da investigação histórica que a propriedade da terra foi originariamente pública. O sistema de sesmarias nasceu em Portugal no século XIV com o objetivo de mitigar por meio da retomada da atividade agrícola, a crise de abastecimento pela qual passava o país,. O monarca D. Fernando criou uma legislação com a finalidade de fixar os trabalhadores à terra e reestruturar o país.

A Coroa portuguesa implantou o sistema de sesmarias no Brasil para promover o desenvolvimento de sua colônia na América, vinculando-a aos seus interesses comerciais e mantendo-a subordinada ao Estado.

Assim, o Brasil teve o seu território submetido a concessões, a partir da colonização iniciada por Martin Afonso de Sousa, com a utilização do instituto das sesmarias, mais especificamente, da Lei de Sesmarias, publicada em Santarém no ano de 1375, por D. Fernando, o Formoso, com a qual buscou corrigir distorções detectadas no uso das terras rurais lusas, fatores determinantes da falta de alimentos, acentuado êxodo rural e ociosidade generalizada.

As Ordenações Filipinas (Livro Quarto, Título XLIII), do final do século XVI, definiram as sesmarias: "São propriamente as dadas de terras casais ou pardieiros que foram ou são de alguns senhorios e que já em outro tempo foram lavrados e aproveitadas e agora não o são". 
Pela leitura da definição acima, percebe-se que em Portugal as sesmarias tinham outro significado. Entretanto, foram aplicadas regras, princípios e institutos do direito português na colônia, sem que a Coroa percebesse as condições completamente diferentes entre os dois países.

A realidade de Portugal era totalmente diferente. Primeiro, as terras do território brasileiro eram virgens, enquanto as portuguesas já haviam sido lavradas e aproveitadas. Segundo, em Portugal a natureza jurídica das sesmarias era de confisco, enquanto no Brasil elas guardavam similitude com o instituto da enfiteuse, pois só se transferia o domínio útil. Terceiro, a extensão territorial do Brasil é imensa. Por tais razões as sesmarias não se adequavam ao Brasil. Além do mais, as sesmarias não tinham uma área definida e variavam conforme a região. As concessões de terras feitas aos mais próximos do poder não só se davam sem critério como extrapolavam os limites permitidos por lei.

Para Bercovici, é possível concluir que a colonização portuguesa não foi um empreendimento metódico e racional, mas feita com desleixo e certo abandono. (BERCOVICI, 2005, p, 118). O autor, nessa mesma obra, elucida que o sistema de sesmarias foi transposto sem qualquer adaptação à realidade da Colônia. E diz mais, que na realidade brasileira, o sistema legal das sesmarias foi praticamente ignorado. As normas específicas para a Colônia só surgiram no final do século XVII, e contribuíram para piorar a situação, ao instituir de vez a confusão normativa.

No mesmo sentido, ALMEIDA (2003) comenta sobre a implantação do sistema das sesmarias no Brasil. Para o autor, além de ter trazido graves sequelas ao regime agrário brasileiro, deu início à formação de grandes latifúndios que existem ainda hoje. E a segunda crítica é que ela foi implantada com base em um critério pessoal e econômico, ocasionando injustiça, pois apenas os ricos eram beneficiados. Os pobres ficavam desprovidos de terra e eram submetidos ao trabalho escravo ou viviam em regime de servidão para o sesmeiro.

Feitosa, Maia e Freitas (2009), analisando o crescimento da agricultura mercantil de exportação no século XVIII, apontam os fatores que contribuíram para a decadência e fim do regime das sesmarias:

O crescimento da agricultura mercantil de exportação em fins do século XVIII e início do século XIX, isto como decorrência da revolução industrial que se processa na Inglaterra, exigindo grande quantidade de insumos, o que só a produção de recursos agrícolas e minerais poderia proporcionar; 2) o acirramento das contradições interindustriais, impondo disputa entre as grandes potências da época pelo controle de mercados, do que as guerras napoleônicas não deixam de constituir exemplo; 3) o fim do monopólio estatal 
do comércio entre Portugal e a colônia brasileira pela Carta Régia de 1808, permitindo a circulação de mercadorias inglesas no território do Brasil-Colônia sem a intermediação do Estado português. (FEITOSA, MAIA E FREITAS, 2009)

Tais fatores põem fim ao regime das sesmarias, em 17 de julho de 1822, poucos meses antes da independência política do Brasil do jugo português. De fato, sem o monopólio estatal do comércio da colônia, a razão de ser do regime das sesmarias perdeu o sentido.

Enfim, as sesmarias acabaram por provocar uma situação insustentável no território brasileiro, com grandes áreas de terra improdutivas, concentração de renda, desigualdade social, regionais e econômicas, atraso na agricultura. Melhor dizendo, não tivemos sesmarias no seu sentido original, mas datas e concessões da Coroa portuguesa passaram a expressão sinônima.

No período colonial, pode-se verificar ainda, que a estrutura agrária concentradora da propriedade no campo, trouxe como consequência o latifúndio, o trabalho escravo e a produção açucareira. A cultura do latifúndio é uma questão que permanece até os dias atuais, em todas as regiões da federação brasileira, motivo de reclamações por uma reformulação desde então.

\subsection{Das Posses}

No período entre 1822 e 1850, sem legislação especifica sobre a política de terras, a posse era a única forma de aquisição de domínio, apenas de fato, sobre as terras brasileiras. Predominava, especialmente, a posse de grandes latifúndios. Para Bercovici (2005), o posseiro, a partir de sua lavoura, estendia suas terras até onde a resistência de outros não colidisse com seus intentos.

Também conhecido como período extralegal ou das posses, a ocupação do território brasileiro foi ainda mais desordenada. As áreas eram apossadas de modo indiscriminado, sem qualquer requerimento às autoridades e sem nenhuma regulamentação feita pelo poder público. O período caracterizou-se como um regime que reconhecia grande valor à posse ou ocupação, as quais passaram a constituir modos de aquisição do domínio até o novo regulamento.

Nessa fase extralegal, as terras brasileiras encontravam-se nas seguintes situações: (i) Proprietários originários de sesmarias, cujos detentores houvessem cumprido os requisitos de lei; (ii) Possuidores legítimos, também originários de sesmarias, mas cujos beneficiários ou sesmeiros não houvessem cumprido os requisitos legais no sentido de obterem a confirmação de doação; (iii) Possuidores sem nenhum título hábil capaz de gerar direitos ao ocupante; (iv) 
Integrando o patrimônio público desde as origens, sem que nunca houvessem sido dadas em sesmaria nem ocupadas por particulares; e (v) Terras devolutas, isto é, aquelas que foram dadas em sesmarias e que posteriormente caíram em comisso, e por isso foram devolvidas ao patrimônio imperial.

\title{
2.3 Da Lei de Terras
}

Em 18 de setembro de 1850 é sancionada pelo Imperador a Lei 601 regulamentada em 30 de janeiro de 1854 pelo Decreto 1.318 que regulariza o quadro dos latifúndios inexplorados e reverte ao domínio público as sesmarias e posses não cultivadas. A partir desta Lei trata-se de forma sistemática a matéria referente às terras no território brasileiro e regulamentam-se a posse e a propriedade. A partir deste marco no cenário jurídico nacional são elaboradas regras que permitem a distinção entre as terras pertencentes ao domínio público e ao particular. A Lei previu o conceito de patrimônio fundiário estatal, próprio e devoluto. Lafayette compara o regime de posse e o regime introduzido pela Lei de Terras, e destaca que a nova lei:

\begin{abstract}
Antes da promulgação da citada lei (de 1850) vigorava o costume de adquirirem-se por ocupação (posse era o termo consagrado) as terras devolutas, isto é, as terras públicas que não se achavam aplicadas a algum uso ou serviço do Estado, províncias ou municípios. A dita Lei aboliu aquele costume, e tornou dependentes de legitimação de posses adquiridas por ocupação primária, ou havidas do primeiro ocupante, até a sua data. (LAFAYETTE, 2004, p. 142)
\end{abstract}

Sodero ensina que esta Lei de Terras não investia contra quem quer que fosse, apenas buscava "disciplinar a propriedade firmada na atividade agrária, realizando tudo que estivesse irregular, com a expedição de títulos de domínio pelo reconhecimento da cultura efetiva e moradia habitual, além de revalidar as sesmarias em comisso, não exploradas. (SODERO,1982, p.16). Bercovici comenta sobre as inovações da Lei de Terras:

O seu art. $3^{\circ}$, modificou o conceito de "terra devoluta". Durante o período colonial "terras devolutas" eram as terras concedidas de sesmaria que voltavam para a coroa devido ao fato de o concessionário não ter preenchido as condições da concessão. Com a lei, "terra devoluta" passou a ser terra vaga, inculta. A aquisição das terras devolutas foi proibida por outro meio que não a compra' sesmarias ou concessões que se achassem cultivadas seriam revalidadas, mesmo que outras condições estabelecidas originariamente não tivessem sido cumpridas (art. $4^{\circ}$ ) as posses mansas e pacíficas - isto é, as não-contestadas ou impugnadas judicialmente seriam legitimadas desde que tivessem sido cultivadas ou houvesse 
princípio de cultura e morada do posseiro ou representante (art. $5^{\circ}$ ). (BERCOVICI, 2005, p.130)

Entretanto, a Lei de Terras não conseguiu solucionar os problemas fundiários. O apossamento das terras públicas continuou, as terras devolutas não foram demarcadas e a consequência foi a desvalorização dessas terras, de modo que não foram vendidas para financiar a imigração. A tentativa do Império de criar núcleos coloniais e financiar a imigração com a venda das terras devolutas a imigrantes não surtiu efeito positivo.

E foi assim que, proclamada a República, o problema das terras devolutas era um dos que os Estados federados brasileiros teriam que resolver, pois o Governo Imperial não conseguiu solucionar.

\section{PERÍODO REPLUBICANO}

No final do século XVIII inicia-se na Inglaterra a industrialização, que só chega ao Brasil no século XX. Neste século, as desigualdades regionais são agravadas, as regiões dotadas de ferrovias e rodovias interligadas aos centros de produção e consumo, bem como de portos marítimos, são beneficiadas.

O período republicano brasileiro começa em 1889 e tem como característica o fenômeno conhecido como coronelismo que decorre da abolição da escravatura, do contingente eleitoral e da adoção do federalismo. Nesse período, o sistema econômico era baseado quase exclusivamente no café. A doutrina cita o café como exemplo de primeiros atos de dirigismo econômico ocorridos em pleno Estado liberal, que se caracterizava por não interferir nas atividades econômicas. A política de valorização do café foi mantida pelo Governo de então. Mesmo com a primeira Constituição do Brasil- República, promulgada em 1891, essa política foi considerada interessante para a União.

Assim, as potencialidades subjetivas que emanavam da propriedade liberal constituíam um instrumento da soberania individual. Entendia-se que o domínio do título de propriedade está dentro do indivíduo e não precisa mais de condicionamento externo, é, portanto, absoluto.

Todavia, o direito de propriedade no Brasil vem passando por modificações desde a época das colônias, assumindo formas conceituais distintas. As normas do Código Civil 
francês serviram de inspiração para um bom número de legislações civis no século XIX, sendo que o Brasil não escapou dessa influência.

Apesar de o primeiro Código Civil brasileiro ter sido editado em 1916, ele já havia sido formulado no fim do século XIX como expressão ultraliberal, colocando a família, a propriedade privada e a autonomia da vontade como pilares do patrimônio jurídico privado.

Apesar das transformações ocorridas em outros países, no Brasil a base da propriedade liberal permaneceu inalterada até a Constituição de 1934, que, sob a influência da Constituição de Weimar de 1919, abriu uma brecha no plano constitucional da concepção liberal-individualista da propriedade privada ${ }^{1}$. Esta, embora continue permitindo a inviolabilidade do direito de propriedade, usa as expressões utilidade pública e interesse social $^{2}$.

É bem conhecido o fato de que o direito de propriedade sempre foi reconhecido na história como um direito fundamental. No entanto, a ênfase dada na definição mudou com o passar do tempo, tanto que nas sociedades contemporâneas este direito deixou de ser absoluto.

No Brasil até o final do século XX os conceitos de propriedade privada eram examinados e tratados de maneira diferente pelo direito civil e pelo direito constitucional, separando os civilistas dos constitucionalistas. Assim, no âmbito das relações civis, as disposições do Código Civil Brasileiro estabeleceram as faculdades do uso, gozo e disposição dos bens. Hoje, a plenitude da propriedade, com seu caráter exclusivo e ilimitado adquire outro aspecto e passa a ser delimitado e condicionado conforme as normas e princípios constitucionais que regulam o direito em geral.

No Código Civil de 1916 a propriedade é conceituada pelo seu aspecto estrutural, ou seja, enquanto estrutura do direito subjetivo do proprietário. Para Clóvis Beviláqua, tal reconhecimento faz com que a propriedade deixe de lado o caráter egoístico originário, entretanto, o que eliminaria o caráter absoluto e individual seriam as limitações ao direito de propriedade. Convém realçar que a função social ainda estava fora de suas cogitações.

\footnotetext{
1 Veja HORTA, Raul Machado, Estudos de Direito Constitucional, Belo Horizonte, Del Rey, 1995.

2 Veja a Constituição Brasileira de 1934, Art. 113.17.
} 
Com o Constitucionalismo Social que tem como marco a Constituição do México de 1917 e com a Constituição de Weimar de 1919 a propriedade muda o seu perfil. A partir de 1918 os direitos privados são relativizados pela função social, o que significa não ser possível a individualização de um interesse particular, individual, isolado, independente do interesse público. A função tem o poder de dar à propriedade um destino, um objetivo, e o adjetivo Social indica que o interesse coletivo está acima do interesse individual do proprietário.

No Brasil, a Constituição Federal de 1934 foi a primeira a tratar implicitamente da função social, que condiciona o exercício da propriedade ao interesse social. É a partir desse momento que o direito de propriedade abandona a concepção romanística clássica e passa a ter finalidades sociais, coletivas. Observe-se que a noção de função social já estava presente implicitamente na constituição de 1934. Embora a Carta Constitucional de 1937 tenha abolido a expressão interesse social do seu texto, a Constituição de 1946, no art.147 adotou a expressão 'bem-estar social'.

Convém registrar que a Emenda Constitucional n.10, de 10.11.1964 à Constituição de 1946, modificou o conceito de propriedade até então vigente, e, o conceito de função social passa a ser estabelecido no Estatuto da Terra, Lei n. 4.504, de 30.11.1964, documento infraconstitucional.

A função social da propriedade privada só apareceu como um dos princípios da ordem econômica e social de forma explícita na Carta Constitucional de 1967, no art.

157 “A ordem econômica tem por fim realizar a justiça social, com base nos seguintes princípios: (...) III- função social”.

Celso Furtado foi responsável pelo Plano Trienal que visava promover reformas de base. De acordo com esse Plano, a estrutura agrária do país era um entrave à aceleração do desenvolvimento da economia nacional; havia então a necessidade de ajustes para o progresso da sociedade. O Plano Trienal identificava a origem do atraso da agricultura brasileira deixando evidente a baixa produtividade da terra e a pobreza das populações no meio rural.

Com o Estatuto da Terra pretendeu-se uma nova distribuição de terras no Brasil, ou seja uma reforma agrária nos moldes do Regime Militar. O que significaria Reforma Agrária, nesse período?

Segundo o Estatuto da Terra, considera-se reforma agrária o conjunto de medidas que visam a promover melhor distribuição de terra, mediante modificações no regime de 
sua posse e uso, a fim de atender aos princípios de justiça social e ao aumento da produtividade.

Fernando Pereira Sodero esclarece que reforma agrária é o processo drástico de redistribuição de direitos sobre a propriedade privada da terra agrícola, promovido pelo Governo, com a ativa participação dos próprios camponeses e objetivando sua promoção humana, social, econômica e política.( SODERO, 1971, p 37)

Raymundo Laranjeira também comunga com a ideia de que a modificação dos direitos sobre a propriedade tem como objetivo a obtenção de maior oferta de gêneros e a eliminação das desigualdades no campo. (LARANJEIRA, 1983, p.114)

Américo Luís Martins da Silva diz que Reforma Agrária é a intervenção que importa na repartição direta da propriedade e do rendimento social agrícola. Para o autor é um programa de governo para promover a repartição da propriedade e da renda fundiária. (SILVA, 2002, p.297)

A reforma agrária, no entendimento de Gilberto Bercovici , é antes de mais nada, “a mudança profunda da estrutura fundiária. Ela é tanto mais necessária, em determinado país, quanto maior for a desigualdade na distribuição de terra. O fundamento básico da reforma agrária é o da função social da propriedade, tendo em vista que a terra é um meio de produção.” Para o autor, a atual estrutura agrária do país constitui “ "grave empecilho à aceleração do desenvolvimento da economia nacional, impondo-se o seu ajustamento às exigências e necessidades de progresso da sociedade brasileira." (BERCOVICCI, 2005, p.151)

Como não houve uma redefinição da estrutura agrária, a concentração da propriedade da terra aumentava de forma injustificável e profundamente danosa à sociedade brasileira.

\subsection{Reforma agrária constitucionalizada}

Um dos principais instrumentos para a realização da reforma agrária no Brasil é a desapropriação. E a Constituição Federal de 1988 previu duas hipóteses dedesapropriação para fins de reforma agrária: a do inciso XXIV, art. $5^{\circ}$ e a do art. 184. Com efeito, estabelecem os referidos mandamentos constitucionais:

Art. $5^{\circ}$, inciso XXIV- A lei estabelecerão procedimento para desapropriação por necessidade pública, ou por interesse social, mediante justa e prévia indenização em dinheiro, ressalvados os casos previstos nesta Constituição. Art. 184. Compete à União desapropriar por interesse social, para fins de reforma agrária, o imóvel rural que não esteja cumprindo a sua função 
social, mediante prévia e justa indenização em títulos da dívida agrária, com cláusula de preservação do valor real, resgatáveis no prazo de até vinte anos, a partir do segundo ano de sua emissão, e cuja utilização será definida em lei.

A desapropriação por interesse social, prevista no art. $5^{\circ}$, inciso XXIV, da Constituição Federal de 1988, é um poder geral do Poder Público, e contribui para uma melhor distribuição de terra na medida em que se pague justa indenização em dinheiro. Qualquer imóvel pode ser desapropriado por interesse social para fins de reforma agrária e melhor distribuição de terras. (SILVA, 2003, p. 297) Questiona-se, aqui, quando o autor afirma que inclusive a pequena e média propriedade rural e a propriedade produtiva estão incluídas. Pois a Constituição Federal diz categoricamente que a pequena e média propriedade e a propriedade produtiva não podem ser objeto de desapropriação para reforma agrária. Merece reflexão.

A reforma agrária é importante para o desenvolvimento nacional desde que seja realizada com políticas agrícolas, não é apenas desapropriar propriedades que não cumprem a função social, é muito mais: é oferecer condições para que os assentados, da reforma agrária, obtenham a tecnologia e o financiamento para que possam investir e produzir para que os assentamentos sejam viáveis. Afinal, para o camponês, a propriedade também é um bem de produção.

A Constituição Federal de 1988 exige que a propriedade rural cumpra a sua função social, mediante o atendimento, simultâneo, de quatro requisitos, apresentados no Título VII, da ordem econômica e financeira, no art.186 que estabelece: (i) aproveitamento racional e adequado; utilização adequada dos recursos naturais disponíveis; (ii) preservação do meio ambiente; (iii) observância das disposições que regulam as relações de trabalho; e (iv) exploração que favoreça o bem-estar dos proprietários e dos trabalhadores.

Importante que esses requisitos sejam atendidos simultaneamente. Convém lembrar que a função social da propriedade rural tem como um dos elementos a produtividade; apropriedade rural é um bem de produção, produz alimentos para a sobrevivência humana.

\subsection{Século XXI e a Reforma Agrária brasileira}

Em 2002, várias entidades da sociedade civil elaboraram um documento que foi entregue ao governo. Esse documento foi transformado no atual Plano Nacional de 
Reforma Agrária. Então, podemos dizer que o atual Plano Nacional de Reforma teve o sua gênese nos movimentos sociais.

Segundo Muniz (2009), o novo Plano Nacional de Reforma Agrária (PNRA) surge como condição para que se impulsione o crescimento econômico com a redistribuição de renda e a construção de uma sociedade moderna e soberana. Este plano tem cinco diretrizes estratégicas, sendo estas:

1. A democratização do acesso à terra;

2. $O$ desenvolvimento rural;

3. A universalização dos direitos essenciais;

4. O desenvolvimento territorial, $e$

5. A política de segurança alimentar.

Embora a reforma agrária não esteja na pauta das prioridades do Estado brasileiro, o Plano Nacional de Reforma Agrária integra um programa do governo como um projeto para a democratização da propriedade rural. Para Muniz (2009), ele representa uma visão ampliada da reforma agrária que faz uma tentativa de mudar a estrutura agrária brasileira, descentralizando a estrutura da propriedade rural e intervindo na estrutura produtiva por meio da garantia do crédito, do seguro agrícola, da assistência técnica, de políticas de comercialização e da garantia do direito de propriedade como um direito fundamental de todos baseado no desenvolvimento territorial sustentável.

O Plano Nacional de Reforma Agrária representa algo novo no que se refere à estrutura agrária. Em vez de determinar um modelo único para todas as regiões do país, o Plano prevê a adequação do modelo de reforma agrária às características de cada região.

Os setores da população diretamente beneficiados pela Reforma Agrária são os camponeses (trabalhadores rurais sem terra), um povo com potencial para novos assentamentos. Todavia, os camponeses atualmente assentados necessitam de infraestrutura e apoio para produzir; um imenso setor da agricultura familiar ainda não se integrou aos instrumentos do plano Safra. Os camponeses cuja situação instável dificulta, quando não constitui uma situação intransponível para obter acesso às políticas agrícolas que poderiam beneficiá-los; as populações ribeirinhas, as comunidades quilombolas, que precisam de reconhecimento dos títulos de propriedade das suas terras e de documentação em geral; os camponeses que ocupam terras indígenas, que precisam ser assentados; os trabalhadores da mineração de extração, que lutam pela criação e reconhecimento de reservas 
de extração mineral; os camponeses afetados pela criação de represas; a juventude rural; as mulheres camponesas, entre outros pobres do meio rural.

Não se pode pensar em um projeto de desenvolvimento econômico e social no meio rural brasileiro se não houver uma visão integrada sobre o rural e a articulação dele com um projeto de desenvolvimento nacional. Para tanto é necessário: (i) discutir o conceito de ruralidade no Brasil; (ii) socializar o conhecimento acumulado dos camponeses e outros habitantes do meio rural; (iii) difundir a pesquisa sobre atual situação do campo, principalmente os assentados da reforma agrária que utilizam práticas agroecológicas, na tentativa de romper com o modelo atual de produção de alimentos em escala. Para pensar o rural é necessário pensá-lo integrado às política públicas socioambiental. Fazer isso não de forma isolada, mas no âmbito dos três Poderes (Legislativo, Executivo e Judiciário).

Para Leff (2013, p. 128), o processo de modernização desloca as economias tradicionais de subsistência, impondo processo de despossessão de terras e saberes, gerando desigualdades sociais pelas condições equitativas de distribuição e acesso aos recursos naturais. Assim, é importante que o Estado introduza reformas democráticas visando incorporar normas socioambientais ao processo econômico atual, e, vise a criação de novas técnicas para controlar o modelo gerado pela lógica do capitalismo. O conceito de ruralidade conectado ao conceito de ambiente possibilita novas perspectivas ao processo de desenvolvimento.

\begin{abstract}
A qualidade de vida como objetivo como objetivo do desenvolvimento sustentável rompe os parâmetros homogêneos de bem-estar e abre a possibilidade de novos indicadores do desenvolvimento humanos que articulam os custos di crescimento com os valores culturais e os potenciais da natureza. (LEFF, 2010, p.325)
\end{abstract}

$\mathrm{Na}$ atual conjuntura, é importante mudar o paradigma cultural e investir em educação no campo de modo a combater o deslocamento dos camponeses para a periferia dos centros urbanos. A construção de uma nova ruralidade depende de políticas públicas voltadas para o desenvolvimento socioambiental. Partindo desta perspectiva, é possível pensar o meio rural como um espaço de articulação de processos de diferentes formas de saberes, capaz de gerar um potencial de desenvolvimento, e não como um potencial de crescimento econômico (agronegócio, monoculturas, produção em escalas) capaz de colocar o país no bloco dos mais ricos do mundo. 


\section{CONSIDERAÇÕES FINAIS}

O latifúndio e a má distribuição de rendas contribuíram para aumentar as desigualdades regionais e sociais, principalmente no meio rural, assim, pode-se compreender a luta dos camponeses por uma reforma agrária de qualidade.

A importância de se discutir a questão agrária, a luta pela terra e a organização dos assentamentos rurais decorre da necessidade de se entender como se dá a continuidade do processo de reforma agrária, já que os assentamentos rurais muitas vezes estão

destinados à não prosperidade, ocasionada pelo "abandono" dos camponeses pelo poder público.

Desde as Sesmarias observam-se pontos negativos, ou seja, a inadequação do instituto transplantado de Portugal sem qualquer adaptação à realidade brasileira. Com o Período das Posses agrava-se ainda mais a situação porque o país fica sem legislação até a Lei de Terras de 1850. Esta passa a regularizar o quadro dos latifúndios inexplorados e reverter ao domínio público as sesmarias e posses não cultivadas. A partir deste marco histórico no cenário jurídico nacional, são elaboradas regras que permitem a distinção entre as terras pertencentes ao domínio público e ao particular.

Inspiradas nas Constituição do México de 1917 e na Constituição de Weimar de 1919, a partir da Constituição brasileira de 1934, as nossas Constituições passaram a tratar a propriedade totalmente diferente das constituições liberais, a propriedade deixou de ser individual e absoluta e passou a ter uma função social. Com o Estatuto da Terra de 1964 pretendeu-se uma nova distribuição de terras no Brasil. Segundo o Estatuto da Terra, considera-se reforma agrária o conjunto de medidas que visam promover melhor distribuição de terra, mediante modificações no regime de sua posse e uso, a fim de atender aos princípios de justiça social e ao aumento da produtividade.

Todavia, a reforma agrária só foi constitucionalizada em 1988. A Constituição Federal dispõe, no art.186 quatro requisitos que a propriedade rural deve cumprir simultaneamente. São eles: (i) aproveitamento racional e adequado; utilização adequada dos recursos naturais disponíveis; (ii) preservação do meio ambiente; (iii) observância das disposições que regulam as relações de trabalho; e (iv) exploração que favoreça o bem-estar dos proprietários e dos trabalhadores.

Desta maneira, embora apresentada no Título VII da Ordem Econômica e Financeira, a reforma agrária está reduzida a possibilidades de desapropriação por interesse 
social, em vez ser tratada como distribuição de terras com políticas agrárias e agrícolas, voltada para o desenvolvimento econômico, humano e socioambiental.

Em 2002 a sociedade civil apresenta um Plano Nacional de Reforma agrária com as seguintes estratégias: a democratização do acesso à terra; o desenvolvimento rural; $a$ universalização dos direitos essenciais; o desenvolvimento territorial, e a política de segurança alimentar. Tal iniciativa foi incorporada ao Estado brasileiro como o denominado II Plano de Reforma Agrária.

Mesmo assim, não se pode negar que existe uma relação profunda entre a concentração fundiária no Brasil atual e o regime das sesmarias adotado por Portugal no Brasil-Colônia. Embora com todos os avanços legislativos, e a participação da sociedade civil organizada, o interesse em relação à reforma agrária, ainda hoje, não está na pauta das prioridades do Estado brasileiro.

\section{REFERÊNCIAS}

ALMEIDA, Roberto Moreira de. Sesmarias e terras devolutas. Revista de Informação Legislativa, Brasília, v. 40, n. 158, p. 309-317, abr./jun. 2003. http://www2.senado.leg.br/bdsf/item/id/865 Acesso em: 02/03/2015

BERCOVICI, Gilberto. Constituição econômica e desenvolvimento: uma leitura a partir da Constituição de 1988. São Paulo: Malheiros, 2005.

BEVILÁQUA, Clóvis. Direito das Coisas, Edição histórica, Rio de Janeiro: Faculdades Integradas Estácio de Sá/Editora Rio, junho de 1977.

FIGUEIREDO, Guilherme José Purvin de. A Propriedade no Direito Ambiental. $4^{\mathrm{a}}$ ed. São Paulo: Revista dos Tribunais, 2010.

LAFAYETTE, Rodrigues Pereira. Direito das Coisas. Brasília: Senado Federal; Superior Tribunal de Justiça, 2004.

LARANJEIRA, Raymundo. Colonização e Reforma Agrária no Brasil, São Paulo: Ed. Civilização Brasileira, 1983.

LEFF, Henrique. Saber Ambiental. Sustentabilidade, Racionalidade, Complexidade, Poder. Rio de Janeiro: Vozes, 2010.

LIMA, Ruy Cirne. Pequena história territorial do Brasil: sesmarias e terras devolutas. Porto Alegre: Sulina, 1954.p.11 
MELO FREITAS, Lorena; MAIA, Fernando Joaquim Ferreira; SOBREIRA FILHO, Enoque Feitosa. "6 $6^{\circ}$ COLÓQUIO INTERNACIONAL MARX E ENGELS." $\quad$ http://www.ifch.unicamp.br/formulario_cemarx/selecao/2009/trabalhos/aocupacao- territorial-brasileira--o-caso-do-regime-sesma.pdf. Acesso:01/03/2015

MEIRELLES, Hely Lopes. Direito Administrativo brasileiro. $20^{\mathrm{a}}$. ed. São Paulo: Malheiros, 1995. p. 455.

MUNIZ, Iranice Gonçalves. La Quetión Agraria em Brasil: propiedad, igualdad y democracia. Barcelona: Pompeu Frabra, 2009.

SCIORILLI, Marcelo. Direito de propriedade e política agrária: evolução, aspectos gerais, restrições, proteção, função social, conformação, instrumentos, limites. Juarez de Oliveira, 2007.

SILVA, Américo Luís Martins. A Ordem constitucional econômica. $2^{\mathrm{a}}$ ed. Rio de Janeiro: Forense, 2003

SODERO, Fernando Pereira. A Reforma Agrária no Brasil, São Paulo: LTr Ed., 1971.

. Curso de Direito Agrário 2 - O Estatuto da Terra, Brasília:

Fundação Petrônio Portela Ministério da Justiça, 1982. 